\title{
Analysis of Green House Gases and Positive Impact of Replacing Traditional Energy with Clean Energy
}

\author{
Chengyu Kuang* \\ Dulwich International High School Zhuhai, Zhuhai, China
}

\begin{abstract}
In this study, the potential sources and detrimental effects that will be caused by the several green house gases are firstly presented. The exact proportions of the green house gas, produced from fossil fuel and the exact proportions of the green house gas that is produced naturally are found out. Next, the author finds out the green house gases that contribute the most to the global warming and their causes. Therefore the proportion of the green house gas that is emitted by the developing countries is found out. In addition, the exact proportion and the amount of sustainable energy that are used to generate electricity in some representative developing countries are analyzed. Subsequently, the author proposes a hypothesis that if these countries have $20 \%$ of clean energy usage in their gross energy consumption, the five representatives effects, which are caused by the green house effect will be mitigated. The result shows that these effects will be mitigated with different extents.
\end{abstract}

\section{Introduction}

Currently, the large amount of green house gas emission has caused multiple global effect, including increase in crop vulnerability to infection, pest infestations, rise of sea level, growth in the number and intensity of the extreme weather, and increase in terms of the severing of the land desertification and the lose of animal habitats. The green house gas in the previous context refers to multiple kinds of gas that have the capacity to take in and give out the heat, which mainly includes water, carbon dioxide, methane, nitrous oxides, and ozone. These effects have tremendous impacts on global economy since that they lead to lots of economic damage and the social cost of the green house gas is very high. It is estimated that the social cost of carbon dioxide in 1994 is 440 billion [1]. It can be seen the proportion of different gases that make up of the global greenhouse gas. Therefore, it is crucial for the government all around the world to take actions in order to cope with this extremely serious issue.

Though this paper will not give the precise actions that the government can take to solve these problems, the author will make a hypothesis that, mathematically, how the adverse effects that mentioned above can be reduced if a proportion of the fossil fuel is replaced by the clean energy, and also talk about how these impacts will be mitigated. The paper starts with a systematic calculation about the precise amount of the green house gas, which includes different main categories of green house gas, that is caused by fossil fuel or the improper use of the energy fuel. Then the author figures out the exact proportions of the green house gases that are produced from fossil fuel and the exact proportions of the naturally produced green house gas, and finds out the green house gases that contributed the most to the global warming and their causes. It is also founded out that the proportion of the green house gas that is emitted by the developing countries. Subsequently, the author finds out the exact proportion and the amount of sustainable energy that they used or the portion of energy that they used to generate electricity in some representative developing countries. Therefore, a hypothesis is proposed that if these representative developing countries have $20 \%$ of clean energy usage in their gross energy consumption, how these five effects mentioned at the beginning of this paragraph will be mitigated.

\section{Analysis of the contributors to the carbon dioxide increase}

\subsection{Current situation of green gas}

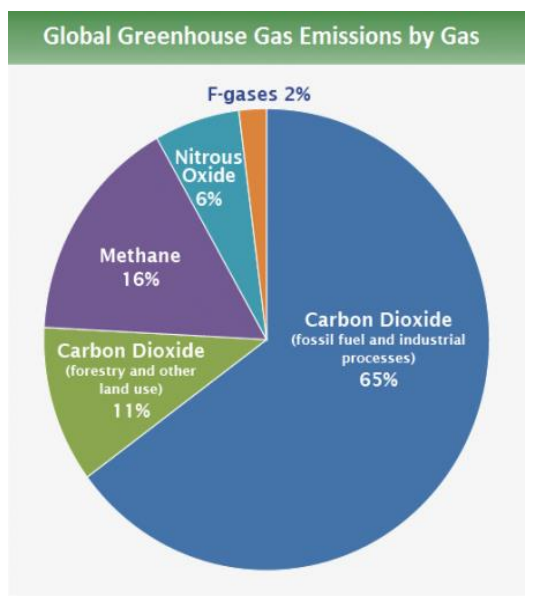

Fig. 1. Global green house gas emission by gas, Source IPCC (2014) 
Since the human activity contributed to the vast majority of carbon dioxide increase over the last 150 years [2], it is reasonable to assume that any calculation regarding the amount of carbon dioxide should be referred to those created by human activities. The amount of greenhouse gas emissions has reached 10,000 metric tons of carbon in 2011, which is nearly 10 times than the amount of fossil fuel emission in 1914 [3]. In Figure 1, it is illustrated that the highest global green house gas contributor is carbon dioxide that is produced by the fossil fuel and industrial processes, and which contributes to around $65 \%$ of the total emission. It is followed by the emission of carbon dioxide that is produced by forestry and land use, methane and nitrogen, of which they contribute to around $11 \%, 16 \%$ and $6 \%$ of the gross emission respectively. As the use of fossil fuel contributes to $78 \%$ of the gross greenhouse gas emissions caused by human activities [2], it can be easily figured out that the total amount of greenhouse gas produced by human activities is approximately around 12820.5 metric tons of carbon. Since some green house gases occurred naturally [4], it is important to illustrate the ratio between the amount of greenhouse gas that is produced naturally and the amount of greenhouse gas that is caused by human activities. Before the industrial revolution (which the author can probably assume that the amount of greenhouse gas produced by human activities is nearly neglected before that time), the concentration of carbon dioxide in the atmosphere is $280 \mathrm{ppm}$, and it experienced a rapid increase since the introduction of industrial revolution, which becomes $370 \mathrm{ppm}$ today in the atmosphere [5]. So the ratio between the synthesis carbon dioxide and naturally occurred carbon dioxide is $1: 3$. The same thing also happened in the concentration of methane. In 1970s, the concentration of methane in atmosphere is $1.52 \mathrm{ppvm}$ (Again since it is the first usable data and the first direct atmospheric methane concentration measurement in the human history, it is assumed that this concentration should be the concentration of methane that occurred naturally), and it is increased steadily for $1 \mathrm{ppvm}$ until 1990. The current atmospheric concentration of methane is $1.77 \mathrm{ppvm}$, so the ratio between the concentration of atmospheric methane produced by human activities and that concentration occurred naturally is quite straightforward, which is $25: 150$. When it comes to ozone, things become more complicated, due to the fact that the factories and vehicles can produce ozone, the concentration of ozone layer has increased by $30 \%$ since the pre-industry era. What is worse is that it also creates an unbalance depth of a ozone layer. The ratio between the concentration of ozone that is produced by human activities and the concentration of the ozone that is occurred naturally is $3: 10$.

\subsection{Main contributors}

\subsubsection{Nitrogen oxides}

Another main contributor to the green house gas is nitrous oxides, which is mainly produced by microbial processes in soil and water, and which can also be regard as the result of extensive uses of chemical fertilizers especially those contains nitrogen. It can only be produced naturally by microorganism. So it is rational about the fact that its concentration starts to increase at the beginning of industrial revolution. For example, its atmospheric concentration in 1988 is 314 ppd.

\subsubsection{CFCs}

The situation changes dramatically when it comes to chlorofluorocarbons (CFCs). Since it does not possess any natural sources, its atmospheric concentration starts to increase since it creation in 1928. Global efforts have been made to prohibited its usage when the scientist discover that its existence in the atmosphere may lead to the exhaustion of the ozone layers decades after it creation. Because of this, it atmospheric concentration starts to be constant, but due to the fact that its average lifetime to exist in the atmosphere is larger than 100 years, an obvious decrease in the atmospheric concentration of CFCs will not be observed in the near future.

\subsubsection{Carbon monoxide}

The last main source of greenhouse gas is carbon monoxide, currently there is no precise measurements about it atmospheric concentration due to the fact that its spatial mobility is very high. But currently its concentration is decreasing. One explanation is that, since its main source is the exhaust gas from the vehicles, the decline of usage of vehicles nowadays may lead to the decrease of the production of carbon monoxide.

\subsection{Other contributors}

\subsubsection{Water vapor}

The scientists attribute the water vapor as the most abundant green house which exists in the atmosphere [6]. Although the water vapor have the largest amount of existence in the atmosphere, the amount of it existence is actually controlled by the earth's temperature because the increase in terms of the earth's temperature can increase the capacity of it surroundings atmospheric air to hold water vapor.[6] Due to it high abundance in the atmosphere, it is extremely crucial to the survival of human lives since it can act as a producer of precipitation and clouds. Owing the amount of water vapor increase as the average of the temperature of the earth increase, the amounts of precipitation and crowds increase as well [6]. Therefore, the water vapor that exists in the atmosphere is not literally caused by human activities, it is in fact caused by the existence of other non-condensable gases such as green house gas.

\subsubsection{Carbon dioxide}

The second largest contributor to the global green house effects is carbon dioxide, which is both cause naturally (it is a minor component in the atmosphere) by volcano eruption and respiration, and by human activities like deforestation, inappropriate land usage, and the use of gasoline and other fossil fuel [7]. Currently, around $23 \%$ of the carbon dioxide 
that's is exist in the atmosphere is caused by human activities.

\subsubsection{Methane}

The third largest causes for green house effect is methane, which is a kind of hydrocarbon gas that is produced both naturally and artificially, by human activities such as decomposition of wastes in landfills, agriculture especially rice cultivation, as well as ruminant digestion and manure management associated with domestic livestock [8]. The reason why methane is also considered to be a green house gas is because, just like carbon dioxide, it can also absorb heat from the sun and prevent it from escaping to the universe.

\subsubsection{Nitrogen oxides}

The fourth largest contributor to the green house gas in the atmosphere is nitrogen oxides, the various kinds of nitrogen oxides is mainly produced by human activities, especially the agricultural practices. The usage of nitrogen fertilizer, the burning of biomass and fossil fuel and the production of nitric acids are the main sources of nitrogen oxide.

\subsubsection{Several approach to reduce their effects}

For different kinds of green house gases, different practices are suggested to decrease it emission. Since the source of green house gas emission can be divided in to 5 categories( Figure 2). The ways to mitigate their emission can also follows the categories. For methane as an example. In it industrial part, the methane emission can be reduced by improving equipment used in oil and gas production, storage and transportation. Methane can also be captured from coal mines and can be used as an energy source. For the agriculture part, reduction in methane emission can be done by changing the fecal management strategy, therefore the methane emission from fecal management and seizure measures can be reduced. In addition, changing animal feeding habits can reduce the discharge of fermentation in the intestines. Also Since the methane emissions in the land field are the main source of methane emissions in the world, controlling methane emissions from waste gas is an effective emission reduction strategy. Another excellent example is nitrogen oxides. For it agriculture part, since nitrogenous fertilisers are cause most of the nitrogen oxides emission in the United States, reducing the nitrogen-based fertiliser usage and using these fertilisers more efficiently can reduce emissions in addition to changing agricultural fertiliser management practices. For it industrial part, Nitric oxides are usually released from the industry through the combustion of fossil fuels, so technological advances and changing the oil usage are effective ways to reduce the nitrogen oxides emission. Besides, the production of adipic acid results in the release of nitrogen oxides, which can be reduced through technological improvement. Besides, carbon dioxide emission can also be reduced via similar approaches. For the domestic part, the building insulation can be reinforced, fuel-efficient vehicles usage can be promoted, and the use of more efficient equipment can also be encouraged to reduce energy consumption and thus $\mathrm{CO} 2$ emissions. Besides, reducing the use of personal energy by turning off lights and electronics when they are not used can reduces the need for electricity. Reducing the distance traveled by cars reduces oil consumption. Both of them can reduce carbon dioxide emissions. In addition, $\mathrm{CO}_{2}$ capture is a technologie that can significantly reduce $\mathrm{CO}_{2}$ emissions from coal-fired power plants, industrial processes and other sources of $\mathrm{CO}_{2}$. For example, carbon dioxide can be collected from the factories before entering the atmosphere, transport carbon dioxide through pipelines and inject carbon dioxide deep into the earth into carefully selected and appropriate underground geological formations. Besides, increase carbon storage by using soil sources other than the normal natural soil or protect carbon storage by preventing soil degradation or improving existing land use management methods are all good ways to reduce $\mathrm{CO}_{2}$ emissions. In order to reduced the amount of green house gas emission, It is also vitally important to decrease the electricity consumptions. So propagandize in saving electricity is also a useful approach.

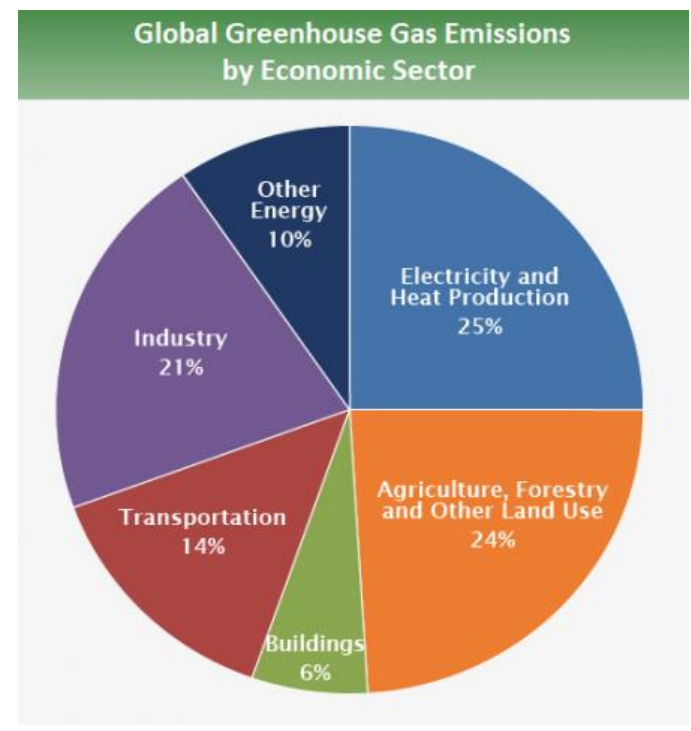

Fig. 2. Global green house gas emission by sector, Source IPCC (2014)

\section{Analysis of the above-mentioned hypothesis}

Table 1 illustrates the countries that are accountable for the emission of $\mathrm{CO}_{2}$ in a ranking series. Among these 20 countries, there are 8 countries that can be categorized as developing countries, which include China, India, Islamic Republic of Iran, Indonesia, Mexico, Brazil, South Africa, Turkey [9]. Since the top 7 countries that contribute the most greenhouse gases have already took account for nearly $70 \%$ of the total global greenhouse emissions [10], and also due to the fact that the top 7 largest carbon dioxide emitters have account for around 20.02GT carbon dioxide, it can be easily calculated that the top 20 largest carbon dioxide emitters have accounted for nearly 26GT carbon dioxide, and which, in turn, account for $90.9 \%$ of the gross global carbon dioxide emission since the gross global carbon dioxide emissions is 
28.6GT [10]. So the author just uses the data from the top 20 carbon dioxide emitter as a representation of the global emissions model. In this model, the developing countries are only accountable for $14.2 \mathrm{GT}$ carbon dioxide emission, which is nearly $49.7 \%$ of the gross carbon dioxide emission for this 20 countries, and the most of the carbon dioxide emissions is from combustion of the fossil fuel [11].

Table 1. The top 20 countries' $\mathrm{CO}_{2}$ emission that are accountable for the emission of $\mathrm{CO}_{2}$ in a ranking series

\section{The 20 countries that emitted the} most carbon dioxide in 2017

\begin{tabular}{|l|l|r}
\hline Rank & Country & $\mathbf{C O}_{2}$ emissions (total) \\
\hline 1 & China & $9.3 \mathrm{GT}$ \\
\hline 2 & United States & $4.8 \mathrm{GT}$ \\
\hline 3 & India & $2.2 \mathrm{GT}$ \\
\hline 4 & Russian Federation & $1.5 \mathrm{GT}$ \\
\hline $\mathbf{5}$ & Japan & $1.1 \mathrm{GT}$ \\
\hline 6 & Germany & $0.7 \mathrm{GT}$ \\
\hline 7 & South Korea & $0.6 \mathrm{GT}$ \\
\hline 8 & Islamic Republic of Iran & $0.6 \mathrm{GT}$ \\
\hline 9 & Canada & $0.5 \mathrm{GT}$ \\
\hline 10 & Saudi Arabia & $0.5 \mathrm{GT}$ \\
\hline 11 & Indonesia & $0.5 \mathrm{GT}$ \\
\hline 12 & Mexico & $0.4 \mathrm{GT}$ \\
\hline 13 & Brazil & $0.4 \mathrm{GT}$ \\
\hline 14 & South Africa & $0.4 \mathrm{GT}$ \\
\hline 15 & Australia & $0.4 \mathrm{GT}$ \\
\hline 16 & United Kingdom & $0.4 \mathrm{GT}$ \\
\hline 17 & Turkey & $0.4 \mathrm{GT}$ \\
\hline 18 & Italy & $0.3 \mathrm{GT}$ \\
\hline 19 & Poland & $0.3 \mathrm{GT}$ \\
\hline 20 & France & $0.3 \mathrm{GT}$ \\
\hline & & \\
\hline
\end{tabular}

For the largest carbon dioxide emissions country, China has long been developing its capacity to use sustainable energy resources. In 2017, renewable energy accounted for $36.6 \%$ of China's total installed electric power capacity, and $26.4 \%$ of total power generation, and the largest portion of the sustainable energy resources is hydroelectric energy [12]. Until 2019, China possesses the largest growing rate of sustainable power in electricity generation, and most of which comes from hydroelectric and wind power. The same thing also happened in other developing countries like India. In 31 March 2020, 35.86\% of India's installed electricity generation capacity is from renewable sources, generating $21.22 \%$ of total utility electricity in the country [13]. The situation changed dramatically when it comes to the developed countries. The sustainable and renewable energy usage in developed countries like USA only contribute to around $11 \%$ primary energy consumption and $17 \%$ domestic electricity generation in 2018 [14]. Which presents a general fact that the vast majority developing countries progress faster than the general developed countries, so therefore the author proposed a hypothesis that if all the developing countries in the above top 20 carbon dioxide contributors use $40 \%$ of sustainable or renewable energy in their total energy consumption and it can therefore be figured out what would happen in terms of that five adverse effects (which are increase in crop vulnerability to infection, increase in pest infestations, increase in sea level, increase in the number and intensity of the extreme weather, increase in land desertification, increase in the lose of animal habitats caused the by greenhouse effect. The sustainable energy usage of China, India, Islamic Republic of Iran, Indonesia, Mexico, Brazil, Turkey contributed to $13 \%$ [12], 7.8\%, 2\%, $6 \%, 16 \%, 8.6 \%$ [15] of their gross primary energy consumption respectively, and $16.8 \%$ [16] to the gross electricity generation in South Africa. In addition, due the fact that, the proportion in these two data (gross primary energy consumption and gross electricity generation) has a around $10 \%$ difference, so it is assumed that the sustainable energy usage of South Africa contributed to $6.8 \%$ of its gross primary energy consumption, thus it can be proposed that if all these 7 developing countries can use $20 \%$ of sustainable energy in their gross primary energy consumption, how that five environmental effects can be alleviated.

\section{Discussion}

Increasing in their proportion of sustainable energy usage to $20 \%$ of their gross primary energy consumption means their emission of $\mathrm{CO}_{2}$ may decrease accordingly. So total emission of the global carbon dioxide that will exist of the world will become 12.08 because the first 20 countries' prediction which present a reduction of $2.21 \mathrm{GT}$, and also according to the ppm and GT exchange $(1 \mathrm{ppm}=17.3$ Gigatonnes of Carbon Dioxide emissions exchange), the reduction of ppm in the atmosphere may be 0.123 [17]. According to that article which illustrates the correlation between the concentration of $\mathrm{CO}_{2}$ and temperature, it predicts that the reduction of $0.123 \mathrm{ppm}$ of $\mathrm{CO}_{2}$ may cause the reduction of 0.01 degree in terms of temperature, and may also have alleviated the consequences caused by green house effect. Since the main consequences caused by the green house effect should be increased in the global temperature may facilitate the rate of the glacier melting, and therefore the sea level and the methane emissions may rise, and threatening the coastal cities. Besides, the increase in the temperature will also facilitate the formation and increase the occurrence of hurricane and other extreme weather since they can only be formed beyond a certain temperature. In addition, the insect and the animals may also be forced to leave, causing devastating amount of insects distinction during the process. By 2050, the number of people that are forced to flee their homes due to extreme droughts or violent floods could reach 140 million. Another devastating effect caused by the global warming is the deforestation. Due to the soil degradation, large number of trees are destroyed, and therefore alleviate the green house effect even further. According to the UN, 30\% of land has been degraded and lost its real value. As the rising temperatures may caused by green house effect may leads to the the the more formation of hurricane, the destruction of agricultural industry and livestock's should also not be negligible as it change the length of the growing season for certain plants, which may cause famine and many deaths. So these facts may probably indicate that if these representatives developing countries reach that hypothesis, the devastating effects may be reduced in a indirect way due to the fact that the reduction in terms of global temperatures 
will lead to the mitigation of these effects. Figure 3 shows the relationship between change of temperature and the solar activity.

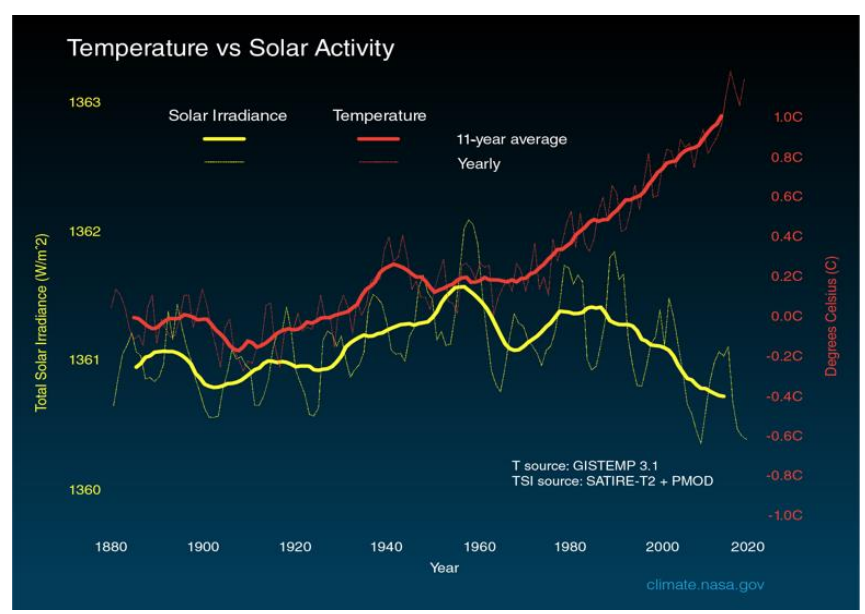

Fig. 3. The relationship between sun radiation and the temperatures

\section{Conclusion}

In conclusion, the author discussed the source and the green house effect of selective green house gases, and roughly calculated the proportions of the green house gas that is produced from fossil fuel and the exact proportions of the green house gas that is produced naturally in this paper. Besides, the proportion of the fossil fuel consumption in some representing developing countries are also listed. The author discussed that if these developing countries only use a certain proportion of fossil, how the global $\mathrm{CO}_{2}$ level as well as some other global problems caused by green house will be alleviated. In this study, some amount of rough calculations have been done and it includes some extent of roughing the numbers and using some outdated data. However, there still needs further investigation.

Firstly I am grateful to the teachers in my high school, who have provided me with all kinds of information. Further, I would like to thank my friends and parents for their encouragement and support. Without all their guidance and impressive kindness, I could not have completed my thesis.

\section{References}

1. S. Fankhauser, The social costs of greenhouse gas emissions: an expected value approach [J]. The Energy Journal, 1994, 15(2).

2. S. Solomon, M. Manning, M. Marquis, et. al. Climate change 2007-the physical science basis: Working group I contribution to the fourth assessment report of the IPCC[M]. Cambridge university press, 2007.

3. Global Greenhouse Gas Emissions Data. (n.d.). Retrieved on November 10, 2020, from https://www.epa.gov/ghgemissions/global-greenhousegas-emissions-data

4. Z. Manning, M. Chen, K. B. Marquis, M. Averyt, Tignor and H. L. Miller (eds.)]. Cambridge University
Press, Cambridge, United Kingdom and New York, NY, USA.

5. Greenhouse Gases. (n.d.). Retrieved on November 10, 2020, from https://www.ncdc.noaa.gov/monitoringreferences/faq/greenhouse-gases.php\#co2

6. The Causes of Climate Change. (n.d.). Retrieved on November $\quad 10, \quad 2020, \quad$ from https://climate.nasa.gov/causes/

7. Inventory of U.S. Greenhouse Gas Emissions and Sinks. (n.d.). Retrieved on November 10, 2020, from https://www.epa.gov/ghgemissions/inventory-usgreenhouse-gas-emissions-and-sinks

8. The Causes of Climate Change (n.d.). Retrieved November $\quad 10, \quad 2020, \quad$ from https://climate.nasa.gov/causes/

9. List of Developing Countries. (n.d.). Retrieved on November 10, 2020, from https://isge2018.isgesociety.com/registration/list-ofdeveloping-countries/

10. Global Greenhouse Gas Emissions Data. (n.d.). Retrieved on November 10, 2020, from https://www.epa.gov/ghgemissions/global-greenhousegas-emissions-data

11. AR5 Synthesis Report: Climate Change 2014. (n.d.). Retrieved on November 10, 2020, from https ://www.ipcc.ch/report/ar5/syr/

12. W. J. Dong, Q. Ye, (18 May 2018). Utility of renewable energy in China's low-carbon transition. Brookings. Retrieved on November 10, 2020.

13. Installed Capacity. (n.d.). Retrieved on November 10, 2020, from http://www.cea.nic.in/monthlyinstalledcapacity.html

14. Primary Energy Production by Source (PDF). US Energy Information Administration. 2017-07-12.

15. Lessons from global experiences for accelerating energy transition in Turkey through solar and wind power(PDF). Shura. Retrieved on November 10, 2020.

16. Global primary energy consumption by source. (n.d.). Retrieved on November 10, 2020, from https://ourworldindata.org/grapher/global-energyconsumption-source

17. Comparing $\mathrm{CO}_{2}$ emissions to $\mathrm{CO}_{2}$ levels. (n.d.). Retrieved on November 10, 2020, from http://www.skepticalscience.com/print.php?r=45) 